\title{
Comparative Study on Biochemical Parameters among Ascochyta Blight Infected Moderately Resistant and Susceptible Chickpea Genotypes
}

\author{
L. Manjunatha ${ }^{1}$, Mamta Sharma ${ }^{2 *}$, P.R. Saabale ${ }^{1}$, B.M. Ravikumara ${ }^{2}$ and N.P. Singh ${ }^{3}$ \\ ${ }^{1}$ Division of Crop Protection, Indian Institute of Pulses Research, Kanpur-208024, UP, India \\ ${ }^{2}$ Legume Pathology Section, ICRISAT, Patancheru, Hyderabad, Telangana, India \\ ${ }^{3}$ ICAR-IIPR, Kanpur, Uttar Pradesh-208024, India
}

*Corresponding author

\begin{tabular}{|l|}
\hline K e y w o r d s \\
Ascochyta, \\
Defense, Genotype, \\
Infection, \\
Inoculation and \\
resistance
\end{tabular}

\section{A B S T R A C T}

The chickpea genotype ICCV 5530, which is moderately resistant and ICCV 4991, susceptible to Ascochyta rabiei were selected to identify the changes in biochemical activity in response to infection by the fungus Ascochyta rabiei. Twelve day old seedlings were inoculated with spore suspension of the pathogen at $5 \times 10^{4}$ spore/ml concentration using a Haemocytometer and incubated under Controlled Environmental Facility (CEF). Sampling was done at 2, 4 and 8 days after inoculation. Chlorophyll 'a', chlorophyll ' $b$ ' and total chlorophyll, total phenol, total soluble sugars, Peroxidase (PO), Polyphenol Oxidase (PPO) Phenylalanine Ammonia Lyase (PAL) activity was assayed by adopting the standard procedure described by various researchers. Higher total chlorophyll content was recorded in un-inoculated leaves of ICCV 4991 and ICCV 5530 genotypes compared to inoculated leaves. But higher total chlorophyll content was recorded in ICCV 5530 than susceptible at all the stages of sampling. The inoculated genotype ICCV 5530 had higher total phenolic content $(11.57 \mathrm{mg} / \mathrm{g}$ fresh wt) than the ICCV $4991(7.32 \mathrm{mg} / \mathrm{g}$ fresh wt). The low concentration of total phenolics in leaves of ICCV 4991 genotype might be the reason for becoming highly susceptible to the disease. Lesser accumulation of the total soluble sugar was observed in ICCV 5530(7.95 mg/g fresh wt.) as compared to ICCV 4991(13.08 $\mathrm{mg} / \mathrm{h}$ fresh wt). However, the expression level of defense related enzymes like PO, PPO and PAL were differed largely in moderately resistant and susceptible genotypes after infection with the pathogen. The increased activity of phenolic compounds, total sugars, CAT, PO, PPO and PAL were found in moderately resistant genotype compared to susceptible one. Therefore, these factors might be involved imparting disease resistance and could be considered for development of broad based resistance against ascochyta blight.

\section{Introduction}

Pulses are vital source of protein with high fibre content and provide ample quantity of vitamins and minerals to the human diet. Keeping in view large benefits of pulses for human health, the United Nations has proclaimed '2016' as the 'International Year of Pulses'. Thus, due attention is required to enhance the production of pulses not only to meet the dietary requirement of protein but also to raise the awareness about pulses for 
achieving nutritional food security and environmental sustainability.

Among the pulses, chickpea (Cicer arietinum L.) is a deep rooted, drought tolerant crop belonging to the family Fabaceae and contributed 48 per cent towards India's total pulses production. The production of chickpea is limited by various biotic and abiotic stresses throughout the world. Among the biotic stresses, Ascochyta blight is considered to be the most destructive diseases of the temperate environments of Indian subcontinent and world reducing the overall yield of the crop (Nene, 1982; Chongo et al., 2000).

Present day cultivars often lose the resistance and become susceptible to diseases. Therefore, mechanism involved in the resistance against fungus during host-pathogen interaction in the resistant and susceptible genotypes are poorly understood. host pathogen Plants possess efficient defense mechanisms against various pathogens where static and dynamic secondary metabolites play important roles either as local or systemic resistance factors in protecting the plants against various pathogens (Redman et al., 1999). The host-pathogen interaction induce signaling molecule in plants system, which lead to production of antimicrobial phenolic substances which are known to participate in a number of biochemical processes. Infection in certain diseases is characterized by increased synthesis of certain precursors of phenolic compounds and oxidation products of phenolics, such as quinines, which exhibit more toxicity to microorganisms.

Defensive enzymes are among the most influential and widely distributed products in the plants. Peroxidase, PPO and PAL were reported in plants treated with various biotic and abiotic inducer (Raghvendra et al., 2007). The plants peroxidases have been implicated in a variety of defense-related processes, including the hypersensitive response, lignification, cross-linking of phenolics and glycoprotein, suberization and phytoalexin production. Catalase is frequently used by cells to rapidly catalyze the decomposition of hydrogen peroxide into less reactive gaseous oxygen and water molecules thus avoiding cellular disintegration (Bolwell and Wojtaszek, 1997). Polyphenol oxidase (PPO) is allowed to leave the chloroplast thylakoid membrane and come in contact with the accumulated phenolic compounds. In the presence of oxygen, PPO oxidizes the phenolic compounds that are in the form of odiphenol to o-quinone (Raj et al., 2006). Higher polyphenol oxidase and peroxidase and lower catalase activity in chickpea's genotypes could be used as parameters for screening against A. rabiei (Kumar et al., 2014). Kaur et al., (2012) reported that higher peroxidase activity could be used as a marker for ascochyta blight resistance in chickpea genotypes Phenylalanine ammonialyase (PAL) is the key enzyme catalyzing the biosynthesis of phenolics and lignin from the aromatic amino acid phenylalanine (Cartea et al., 2010). In resistance to chickpea ascochyta blight, biochemical defense enzymes such as polyamine, diamine oxidase and peroxidase and PAL suggested to play a significant role in regulating the accumulation of phenolics and phytoalexins in response to infection (Peltonen et al., 1998).

The present study was focused on understanding the role of phenols and biochemical enzymes in defense against Ascochyta rabiei under compatible and incompatible reaction with chickpea genotypes.

\section{Materials and Methods}

The present investigation was carried out during 2015-16 under Controlled Environmental Facility (CEF) in the division 
of Kanayo F Nwanze Crop Protection Division, Legume Pathalogy ICRISAT, Patancheru, Hyderabad.

Moderately resistant (ICCV 5530) and susceptible (ICCV 4991) to Ascochyta rabiei of chickpea genotypes were raised in a greenhouse under the conditions of $25 \pm 1^{\circ} \mathrm{C}$ temperature for 12 days. The fungus was mass multiplied from single conidial isolate by inoculating soaked and autoclaved kabuli seeds. The inoculated seeds were incubated at $20 \pm 1^{\circ} \mathrm{C}$ for 8 days with a 12 -h photoperiod. Twelve days after incubation, spore suspension was prepared by soaking A. rabiei infected kabuli chickpea seeds in sterilized distilled water for 30 minutes and vortexed for 2-3 minutes to dislodge the spores from the seeds. The concentration of the double-layered muslin cloth filtered spore suspension was adjusted to $5 \times 10^{4}$ conidia/ml using a Haemocytometer. The trays with 12 day old seedlings were transferred to Controlled Environmental Facility (CEF) to acclimatize for 24 hours before inoculation.

After 24 hours; spore suspension of A. rabiei $\left(5 \times 10^{4}\right.$ conidia/ml $)$ was sprayed on the moderately resistant and susceptible genotypes until runoff. The seedlings were allowed to dry partially for 30 minutes of post inoculation to avoid dislodging of spores. In the CEF air temperature $\left(20 \pm 1^{\circ} \mathrm{C}\right)$, relative humidity (95$100 \%$ continuously for $96 \mathrm{hr}$ and thereafter 6$8 \mathrm{~h}$ a day till the completion of experiment) and photoperiod (12h, 1500 lux light intensity provided with fluorescent lights) was maintained throughout the experiment. An observation for the Per cent Disease Index (PDI) and sampling was done at 2, 4 and 8 days after inoculation. The plants were randomly collected and assessed for per cent disease severity using 1 to 9 rating scale as described by Reddy and Singh (1984) and further the grades were converted to PDI using the formula given by Wheeler (1969).

\section{Sampling and enzymatic study}

The chickpea leaves inoculated with A.rabiei were collected randomly at 2, 4 and 8 days after inoculation along with control plants to assess the biochemical changes and host pathogen interaction. The leaf samples collected were dipped in liquid nitrogen to stop plant metabolic activity, then placed in ice box containing ice cubes and brought to the laboratory.

Chlorophyll 'a', chlorophyll ' $b$ ' and total chlorophyll were estimated following the method described by Arnon (1949). The total phenol in plant samples was estimated following Folin- Ciocalteau reagent (FCR) method (Bray and Thorpe, 1954). In Catalase (CAT) estimation, $500 \mathrm{mg}$ of fresh frozen leaf sample were homogenized with $3 \mathrm{ml}$ of 25 $\mathrm{mM}$ sodium phosphate buffer ( $\mathrm{pH}$ 7.8). Homogenate was transferred into an Eppendorf tube and centrifuged at 20,000 rpm for $30 \mathrm{~min}$ at $4^{\circ} \mathrm{C}$, and then, the supernatant was used for enzyme assay. The reaction mixture $(2,000 \mu \mathrm{L})$ consisted of $1,400 \mu \mathrm{L} 25$ $\mathrm{mM}$ Na-phosphate buffer, $500 \mu \mathrm{L}, 10 \mathrm{mM}$ $\mathrm{H}_{2} \mathrm{O}_{2}$ and $100 \mu \mathrm{L}$ crude enzyme extract. CAT activity was assayed by measuring $\mathrm{H}_{2} \mathrm{O}_{2}$ consumption at $240 \mathrm{~nm}$ for $1 \mathrm{~min}$ in spectrophotometer. Enzyme activity was expressed as CAT units' min-1 mg-1 protein.

Total soluble sugars were estimated according to the method described by Yoshida et al., (1971) using anthrone reagent. The peroxidase activity was assayed by measuring the oxidation of guaiacol in the presence of hydrogen peroxide into water at $470 \mathrm{~nm}$ as described by Hammer Schmidt et al., (1982). Activity was expressed as the increase in absorbance at $470 \mathrm{~nm}$ in min-1mg-1 of protein. PPO activity was determined as per the procedure given by Mayer et al., (1965). Five hundred milligram of leaves was used for polyphenol oxidase estimation: the reaction 
mixture consisted of $1.5 \mathrm{ml}$ of $0.1 \mathrm{M}$ sodium phosphate buffer ( $\mathrm{pH}$ 6.5) and $200 \mu$ of the enzyme extracts. To start the reaction, $200 \mu \mathrm{l}$ of $0.01 \mathrm{M}$ catechol was added and the activity was expressed as changes in absorbance at $495 \mathrm{~nm} / \mathrm{min} / \mathrm{g}$ fresh weight of leaf tissue. Assay and determination of PAL was carried out by adopting the procedure given by Sadasivam and Manickam (1996). The absorbance was read at $290 \mathrm{~nm}$ in UV Spectrophotometer. The quantity of cinnamic acid formed was calculated by using a standard curve of cinnamic acid. The results of each experiment are average of two replications.

\section{Results and Discussion}

The inoculation of Ascochyta rabiei fungus onto chickpea genotypes, ICCV 4991(S) and ICCV 5530(MR) results in extreme changes in biochemical factors and disease severity were observed. The Ascochyta rabiei inoculated genotypes (ICCV 4991 and ICCV 5530) showed a wide range of symptoms depending on their level of resistance and genetic makeup. Susceptible genotype ICCV 4991 start developed disease symptoms at 4 days after inoculation as water-soaked lesions on the upper leaves and stem. At 10 days after inoculation, 100 per cent disease severity was observed on susceptible genotype ICCV 4991 but moderately resistant genotype ICCV 5530 did not show much increase in disease severity.

The study on effect of chlorophyll content $(\mathrm{mg} / \mathrm{g}$ fresh wt) in resistant and susceptible genotypes after inoculation with Ascochyta rabiei revealed that at different DAI, the chl' $a$ ' content was differed. In susceptible genotypes, there was decrease of 23.33, 10.98 and 55.68 per cent in chl-'a' content was observed in diseased leaf over healthy ones (Table 1). Overall, 6.20 per cent more of chl' $a$ ' was recorded in resistant genotypes than susceptible ones. Over all, there was 37.24 per cent more of chl-b was recorded in resistant genotypes than susceptible ones. The study revealed that at different days after inoculation with the pathogen, the total chlorophyll content differed significantly. Among the genotypes, resistant genotypes recorded higher total chlorophyll content than susceptible genotype. Whereas, in diseased leaf showed 6.82 per cent more of total chlorophyll in moderately resistant as compared to susceptible genotype. Overall, there was 18.86 per cent change in total chlorophyll content in resistant genotype as compared to susceptible one.

Total soluble sugars ( $\mathrm{mg} / \mathrm{g}$ fresh wt.) of leaves of resistant and susceptible genotypes were estimated. Among the genotypes resistant genotype recorded $7.81,7.99$ and $8.06 \mathrm{mg} / \mathrm{g}$ fresh wt of total soluble sugars and susceptible genotype recorded $13.09,13.14$ and 13.01 $\mathrm{mg} / \mathrm{g}$ fresh wt of total soluble sugars when inoculated with $A$. rabiei at 2, 4, and 8 DAI. The total soluble sugar content of resistant genotype ICCV 5530 was less than susceptible genotype ICCV 4991 (Table 2).

The plant-pathogenic fungal, bacterial and viral interactions, which showed that certain common phenols and phenolic substances are toxic to pathogens, which have long been considered as important defense related compounds whose levels are naturally high in the resistant varieties of many crops (Gogoi et al., 2001) and accumulates in plants after infection, especially in resistant varieties. Sugars could limit the spread of the pathogen by isolating the infected cells, and protect the tissues against water loss (Herbers et al., 1996). Soluble sugars directly and indirectly play a significant role in resistance processes. A high concentration of soluble sugars may directly limit the pathogen colonization of the cells as a result of increased osmotic potential (Farrer, 1989). 
Phenolic compounds may involve in enhancing the mechanical strength of host cell walls by the synthesis of lignin and suberin compounds that are involved in the construction of physical barriers that can obstruct the spread of pathogens (Ngadze et $a l ., 2012)$. The total phenol content at different days after inoculation is depicted in Table 2. In the present study, the amount of total phenols differed significantly among the two genotypes. The resistant genotype ICCV 5530 recorded highest amount of phenol $(\mathrm{mg} / \mathrm{g}$ fresh wt) both in healthy $(8.295,9.525,12.33)$ and inoculated one $(10.21,11.05,13.45)$ at 2 , 4 and 8 days after inoculation. And also, the amount of total phenols was found decreased in inoculated susceptible genotype ICCV 4991 at all the stages of inoculation, while increased in inoculated resistant genotype ICCV 5530 as compared to their non-inoculated plants. This higher amount of phenols in these plants has been correlated with enhanced resistance to A.rabiei as the accumulation of total phenols is usually found to be higher in resistant genotypes compared to susceptible ones (Velazhahan and Vidhyasekaran, 1994).

Catalase activity (change in absorbance min-1 mg-1 protein) increased in resistant genotype (ICCV 5530) after inoculation with A. rabiei at all the stages (2, 4 and $8 \mathrm{DAI})$ of sampling (11.39, 13.90, and 15.93). In susceptible genotype (ICCV 4991) there was slight increase at 2 DAI (9.48) and then declined $(8.65,6.44)$ to the level below the enzyme activity present in uninoculated control plants $(9.00,8.75)$ at 4 and 8DAI (Table 3). These results suggests that catalase might also be involved in defense mechanism of chickpea against $A$. rabiei by detoxifying the toxic oxygen derivatives, that are considered as common features of stress conditions (Foyer et al., 1994).When plants are exposed to different stresses either biotic or abiotic, results in shifting of their metabolism towards oxidative direction and plant mobilize the anti- oxidative defence mechanisms by several stress enzymes like peroxidase and catalase, in order to eliminate the effect of free radicals (Gill and Tuteja, 2010).

Increased PO activity (change in absorbance at 470 min-1mg-1 of protein) was recorded in the resistant genotype ICCV 5530 (1.10) compared to susceptible genotype ICCV 4991 (0.72) (Table 3). Initially there was a slight increase in the PO activity (0.40) in the leaves of susceptible genotype but after 4 and 8DAI it was declined $(0.25,0.11)$. In resistant variety, however activity continued to increase till 8DAI with A. rabiei. The activity of PPO in healthy leaves of resistant genotype ICCV 5530 was higher $(0.87,0.64,0.05)$ than the corresponding leaves of susceptible genotype ICCV 4991 (0.34, 0.23, 0.01). Two days after inoculation, increased PPO activity was observed in susceptible genotype inoculated with $A$. rabiei (0.61), and then declined at later stages of sampling $(0.04,0.11)$ (Table 3$)$.

The above results are supported by Nawar and Kuti (2003), according to them an increase in peroxidase activity is considered as preliminary indicator for resistance to chocolate spot disease of broad beans. These compounds act as a barrier against pathogen invasion. Accumulation of protein and peroxidase are the part of defense mechanisms against plant pathogens (Sarwar et al., 2011). Hassan et al., (2007) also revealed that increased peroxidase activity in faba bean in response to inducer molecule showed resistance against chocolate spot disease. Plants have complex systems to adapt to biotic and abiotic stresses. Among the response to stresses, increased production of Reactive Oxygen Species (ROS) is one of them. ROS are formed due to incomplete reduction of oxygen. ROS include a variety of short and long-lived molecules such as superoxide, hydroxyl radicals and hydrogen peroxide (Apel and Hirt, 2004). 
Table.1 Content of chlorophyll a, chlorophyll b and total chlorophyll ( $\mathrm{mg} / \mathrm{g}$ fresh wt.) in chickpea genotypes at different days after inoculation (DAI) with A. rabiei

\begin{tabular}{|c|c|c|c|c|c|c|c|c|c|}
\hline \multirow[t]{2}{*}{ Parameter assayed } & \multirow{2}{*}{$\begin{array}{l}\text { Days after } \\
\text { inoculation } \\
\text { (DAI) }\end{array}$} & \multicolumn{3}{|c|}{ Genotype ICCV 4991} & \multirow{2}{*}{$\begin{array}{l}\text { Per } \\
\text { cent } \\
\text { change }\end{array}$} & \multicolumn{3}{|c|}{ Genotype ICCV 5530} & \multirow{2}{*}{$\begin{array}{l}\text { Per cent } \\
\text { change }\end{array}$} \\
\hline & & $\begin{array}{c}\text { Healthy } \\
\text { (mg/g) }\end{array}$ & \multicolumn{2}{|c|}{$\begin{array}{c}\text { Inoculated } \\
(\mathrm{mg} / \mathrm{g})\end{array}$} & & \multicolumn{2}{|c|}{$\begin{array}{c}\text { Healthy } \\
\text { (mg/g) }\end{array}$} & $\begin{array}{c}\text { Inoculated } \\
(\mathrm{mg} / \mathrm{g})\end{array}$ & \\
\hline \multirow[t]{4}{*}{ Chl a } & 2 & 29.03 & \multicolumn{2}{|c|}{23.53} & 23.33 & \multicolumn{2}{|c|}{27.91} & 26.66 & 4.66 \\
\hline & 4 & 26.92 & \multicolumn{2}{|c|}{24.25} & 10.98 & \multicolumn{2}{|c|}{29.30} & 23.46 & 24.88 \\
\hline & 8 & 30.96 & \multicolumn{2}{|c|}{19.88} & 55.68 & \multicolumn{2}{|c|}{29.47} & 20.70 & 42.31 \\
\hline & Mean & 28.97 & \multicolumn{2}{|c|}{22.56} & 28.41 & \multicolumn{2}{|c|}{28.89} & 23.61 & 22.36 \\
\hline Chl b & 2 & 20.41 & 17.5 & & 16.54 & 22 & 77 & 22.52 & 1.09 \\
\hline & 4 & 21.22 & 14.1 & & 50.52 & 21 & 15 & 20.47 & 3.31 \\
\hline & 8 & 20.93 & 12.7 & & 64.17 & 22 & 45 & 20.95 & 7.15 \\
\hline & Mean & 20.85 & 14. & & 41.03 & & 12 & 21.31 & 3.79 \\
\hline Total chl & 2 & 47.53 & 39.3 & & 20.67 & & 04 & 45.18 & 4.12 \\
\hline & 4 & 45.84 & 35. & & 27.68 & & 61 & 42.35 & 17.13 \\
\hline & 8 & 50.21 & 32. & & 53.71 & & 06 & 40.94 & 22.26 \\
\hline & Mean & 47.86 & 35.9 & & 32.99 & & 90 & 42.82 & 14.19 \\
\hline Table.2 Concent & $\begin{array}{l}\text { ation of To } \\
\text { different }\end{array}$ & $\begin{array}{l}\text { al solubl } \\
\text { ays afte }\end{array}$ & $\begin{array}{l}\text { sugar } \\
\text { inocu }\end{array}$ & & $\begin{array}{l}\text { Total p } \\
\text { (DAI) }\end{array}$ & 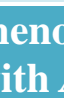 & & $\begin{array}{l}\text { hickpea g } \\
\text { iei }\end{array}$ & notypes at \\
\hline Total soluble sugars & 2 & 20.12 & 13. & & 53.71 & & 22 & 7.81 & 43.66 \\
\hline (mg/g fresh wt) & 4 & 19.82 & 13. & & 50.84 & & 71 & 7.99 & 59.07 \\
\hline & 8 & 20.96 & 13. & & 61.11 & & 08 & 8.06 & 49.88 \\
\hline & Mean & 20.30 & 13.1 & & 55.20 & & 00 & 7.95 & 50.92 \\
\hline Total phenols(mg/g & 2 & 8.23 & 7.3 & & -11.11 & & 95 & 10.21 & 23.14 \\
\hline fresh wt) & 4 & 9.42 & 5.8 & & -38.37 & & 25 & 11.05 & 16.06 \\
\hline & 8 & 11.28 & 8.8 & & -21.67 & & 33 & 13.45 & 9.12 \\
\hline & Mean & 9.64 & 7.3 & & -23.72 & & 05 & 11.57 & 16.11 \\
\hline $\begin{array}{l}\text { Table.3 Concentratic } \\
\text { and susceptible chick }\end{array}$ & $\begin{array}{l}\text { n of defens } \\
\text { pea genotyr }\end{array}$ & ve enzyyn & $\begin{array}{l}\text { es viz. } \\
\text { arent d }\end{array}$ & & $\begin{array}{l}\text { PPO, P } \\
\text { fter ino }\end{array}$ & a & & $\begin{array}{l}\text { talase activ } \\
\text { AI) with } A\end{array}$ & $\begin{array}{l}\text { ity in resistant } \\
\text { scochyta rabiei }\end{array}$ \\
\hline Enzymes assayed & DAI & & enotype & ICCV & 4991 & & & Genotype & ICCV 5530 \\
\hline & & Healthy ( & mg/g) & Inoc & ulated (m & & Hea & thy (mg/g) & Inoculated $(\mathrm{mg} / \mathrm{g})$ \\
\hline & 2 & 0.35 & & & 0.40 & & & 0.53 & 1.00 \\
\hline Peroxidase (PO) change & 4 & 0.70 & & & 0.25 & & & 0.71 & 0.85 \\
\hline in absorbance/min/mg of & 8 & 0.19 & & & 0.11 & & & 1.35 & 1.45 \\
\hline protein & Mean & 0.41 & & & 0.72 & & & 0.86 & 1.10 \\
\hline Polyphenol $\quad$ oxidase & 2 & 0.34 & & & 0.61 & & & 0.87 & 0.93 \\
\hline (PPO) (Change in & 4 & 0.23 & & & 0.04 & & & 0.64 & 0.71 \\
\hline absorbance $/ \mathrm{min} / \mathrm{mg}$ & 8 & 0.01 & & & 0.11 & & & 0.05 & 0.33 \\
\hline fresh weight & Mean & 0.19 & & & 0.25 & & & 0.52 & 0.66 \\
\hline Phenylalanine ammonia & 2 & 1.71 & & & 2.04 & & & 2.17 & 2.55 \\
\hline lyase (PAL) nmol & 4 & 2.12 & & & 1.72 & & & 1.88 & 2.11 \\
\hline transcinnamic & 8 & 1.79 & & & 1.77 & & & 1.79 & 2.63 \\
\hline $\mathrm{acid} / \mathrm{min} / \mathrm{mg}$ protein & Mean & 1.87 & & & 1.84 & & & 1.951 & 2.436 \\
\hline Catalase(CAT) (Change & 2 & 7.38 & & & 9.48 & & & 10.01 & 11.39 \\
\hline in absorbance/min $/ \mathrm{mg}$ of & 4 & 9.00 & & & 8.65 & & & 10.84 & 13.90 \\
\hline protein) & 8 & 8.75 & & & 6.44 & & & 14.42 & 15.93 \\
\hline & Mean & 8.38 & & & 8.19 & & & 11.76 & 13.74 \\
\hline
\end{tabular}


The level of ROS is maintained to optimum level by ROS-scavenging enzymes such as PPO, PO and CAT. Peroxidase also produces free radicals and hydrogen peroxide which are toxic to many microorganisms (Pena and Kuc, 1992). In chemically induced plants, Peroxidase activity was significantly increased as compared to un-inoculated plants (Chaudhary et al., 2001). Early and enhanced expression levels of many defensive enzymes are the main factors of plant resistance to fungus. The PO and PPO activity was observed higher in resistant seedlings than in susceptible seedlings indicates that PO and PPO might have played a considerable role in enhancing host resistance.

In the phenylpropanoid metabolism, PAL is the primary enzyme plays a major role in the synthesis of a number of defense-related secondary metabolites such as phenols and lignin (Hemm et al., 2004). The activity of PAL affects biosynthetic pathways of phenolic compounds (Jayaraj et al., 2010). The activity of PAL increased at 2, 4 and 8 days after inoculation with Ascochyta rabiei in resistant genotype ICCV 5530 (2.55, 2.11 and 2.63). Increase was more pronounced in resistant genotype ICCV 5530 than in susceptible ones (Table 3). PAL activity was higher in inoculated plants of resistant genotype $(2.55,2.11$ and 2.63$)$ than in the susceptible genotype ICCV 4991 (2.04, 1.72, and 1.77). There was an increase in the activity of PAL in susceptible genotype at 2 DAI (2.04) with A. rabiei pathogen then declined $(1.72,1.77)$ at 4 and 8 DAI.

Our findings indicated that phenolic compounds, total sugars, CAT, PO, PPO and PAL played an active role in disease resistance against ascochyta blight of chickpea. The pre-infectional presence of high level of phenolics and post-infectional increase in defense enzymes in incompatible reaction may have further role in disease resistance; thus, additional studies are needed to characterize the phenolic compounds and antioxidative enzymes involved in host pathogen interaction. The higher quantities of defense related proteins such as PAL, PPO and $\mathrm{PO}$ in insect infested tissues governs stronger resistance. These enzymes are also actively involved in biosynthesis of defensive enzymes e.g. PAL is involved in the formation of phenolics through phenylpropanoid pathway (Shafique et al., 2014).

Increased biochemical activity during plant fungus interaction is an important feature of resistance to pathogen. Constitutively induced defensive enzymes and level of phenolic compounds expressed in the genotypes are actively involved in imparting resistance to A.rabiei and also be considered as biochemical markers for development of broad based and durable resistance against ascochyta blight disease.

\section{Acknowledgment}

Authors are grateful to ICAR for providing fund for professional attachment training at ICRISAT. I sincerely acknowledge Dr G. P. Dixit, Coordinator (AICRP on chickpea), IIPR, Kanpur for their moral support and encouragement towards my research goals.

\section{References}

Apel, K. and Hirt, H. 2004. Reactive oxygen species: metabolism, oxidative stress, and signal transduction. Annu. Rev. Plant Biol., 55, 373-399

Arnon, D.I. 1949. Copper enzyme in isolate chloroplasts polyphenol oxidase in Beta vulgaris. Plant Physiology. 24, 1-15

Bolwell, G.P and Wojtaszek, P. 1997. Mechanisms for the generation of reactive oxygen species in plant 
defence-a broad perspective. Physiol. Mol. Plant Pathol, 55, 347-366.

Bray H.G and Thorpe, W.Y. 1954. Analysis of phenolic compounds of interest in metabolism. In: Moth. Biochem Annal (Ed.) GLICK. D. Intersarnae Publishing Inc., New York, 1, 27-52.

Cartea, E. M., Francisco, M., Soengas P and Velasco, P. 2010. Phenolic compounds in Brassica vegetables. Molecules. 6, 251-280.

Chaudhry, M.H.Z., Sarwar, N and Chaughati F.A. 2001. Biochemical changes in chickpea plant after induction treatment with simple chemical for systemic resistance against Ascochyta blight in the field. Journal of the Chemical Society of Pakistan, 23(3):182-186.

Chongo, G., Buchwaldt, L. Anderson K. and Gossen B.D. 2000. Saskatchewan chickpea disease survey,-1999. Can. Plant Dis. Surv., 80:86-87.

Farrar, J.F. 1989. Fluxes and turnover of sucrose and fructans in healthy and diseased plants. J. Plant Physiol., 134, 137-340.

Foyer, C. H., Descourvieres, P and Kunert, K. J. 1994. Protection against oxygen radicals: an important defence mechanism studied in transgenic plants. Plant cell and Environment. 17:507523.

Gill, S. S and Tuteja, N. 2010. Reactive oxygen species and antioxidant machinery in abiotic stress tolerant in crop plants. Plant Physiol. Biochem., 48:909-930.

Gogoi. R.., Singh, D. V and Srivastava, K. D. 2001. Phenols as a biochemical basis of resistance in wheat against Karnal bunt. Plant Pathology. 50:470-476.

Hammerschimidt, R., Knuckles, E.M and Kuc, J. 1982. Association of enhanced peroxidase activity with induced systemic resistance of cucumber to Colletotrichum lagenarium.
Physiological Plant Pathology. 20:7382.

Hassan, M. E. M., El-Rahman, S. S. A., ElAbbasi, I. H and Mikhail, M. S. 2007. Changes in peroxidase activity due to resistance induced against faba bean chocolate spot disease. Egypt. J. Phytopathol., 35:35-48.

Hemm, M.R., Rider, S. D., Ogas, J., Murry, D. J and Chapple, C. 2004. Light induces phenylpropanoid metabolism in Arabidopsis roots. Plant J. 38:765778.10.1111/j.1365-313X.2004.02089.x

Herbers, K., Meuwley, P., Frommer, W. B., Metraux, J. P and Sonnewald, U. 1996. Systemic acquired resistance mediated by ecotopic expression of invertase: possible hexose sensing in the secretory pathway. Plant Cell, 8:793-803.

Jayaraj, J., Bhuvaneswari, R.., Rabindran, R.., Muthukrishnan, $\mathrm{S}$ and Velazhahan, R. 2010. Oxalic acid-induced resistance to Rhizoctonia solani in rice is associated with induction of phenolics, peroxidase and pathogenesis-related proteins. $J$ Plant Interact. 5:147-157. 10.1080/17429140903291012

Kaur, L., Singh V.P and Gupta, A.K. 2012. Peroxidase: a marker for Ascochyta blight resistance in chickpea. Archives of Phytopathology and Plant Protection. 45 (1):42-46.

Kumar, P., Sangwan, M. S., Mehta, N and Kumar, S. 2014. Anti-oxidative enzyme changes associated with chickpea calli tolerant to Ascochyta rabiei culture filtrate. Journal of Environmental Biology. 35:491-496.

Mayer, A.M., Harel, E and Shaul, R.B. 1965. Assay of catechol oxidase a critical comparison of methods. Phytochem. 5:783-789.

Nawar, H. F and Kuti, J. D. 2003. Wyerone acid phytoalexin synthesis and peroxidase activity as markers for resistance of broadbean to chocolate 
spot disease. J. Phytopathol., 151:564570.

Nene, Y. L. 1982. A review of Ascochyta blight of chickpea. Trop. Pest Manag., 28, 61-70.

Ngadze E., Icishahayo, D., Coutinho, T.A and van der Waals, J.E. 2012. Role of polyphenol oxidase, peroxidase, phenylalanine ammonia lyase, chlorogenic acid, and total soluble phenols in resistance of potatoes to soft rot. Plant Dis. 96,186-192.

Peltonen, S., Mannonen, L and Karjalainen, R. 1998. Elicitor induces changes of phenylalanine ammonia lyase activity in barley cell suspension cultures. Pl. Tiss. Organ. Cult., 50:185-193.

Pena, M. and. Kuc, J. A. 1992. Peroxidase generated hydrogen peroxidase as source of antifungal activity in vitro and on tobacco leaf disks. Phytopathol., 82:696-699.

Raghvendra, V. B., Lokesh, S., Govindappa, M and Vasanth, K.T. 2007. Dravyaas, an organic agent for the management of seed borne fungi of sorghum and its role in the induction of defense enzymes. Pest. Biochem. Physiol., 89:190-197.

Raj, S.N., Sarosh, B.R and Shetty, H.S.2006. Induction and accumulation of polyphenol oxidase activities as implicated in development of resistance against pearl millet downy mildew disease. Funct. Plant Biol. 33:563-571.

Reddy, M.V. and Singh, K.B. 1984. Evaluation of world collection of chickpea germplasm accessions for resistance to Ascochyta blight. Plant Disease, 68:900-901.

Redman, S., Regina, S., Freeman, D. R., Clifton, J., Morrel, G., Brown, R and Rodiriguez, J. 1999. Biochemical analysis of plant protection afforded by a nonpathogenic endophytic mutant of Colletotrichum magna. - Plant Physiol., 119:795-804.

Sadasivam, S and Manickam, A. 1996. Biochemical methods II edition New Age International (P) Limited, pp. 256.

Sarwar, N., Zahid, M.H., Ashfaq, S and Jamil, F.F. 2011. Induced Systemic Resistance In Chickpea Against Ascochyta Blight By Safe Chemicals. Pak. J. Bot., 43(2):1381-1387.

Shafique, S., Ahmad, A., Shafiquea, S., Anjuma, T., Akrama, W., Bashir, Z. 2014. Determination of Molecular and Biochemical Changes in Cotton Plants Mediated by Mealybug. Wageningen Journal of Life Sciences 70-71:39-45.

Velazhahan, R. and Vidhyasekaran, P. 1994. Role of phenolic compounds, peroxidase and polyphenol oxidase in resistance of groundnut to rust. Acta Phytopathologica. 29: 23-29.

Wheeler, B.E.J. 1969. An Introduction to Plant Diseases, John Wiley and Sons Limited, London, Pp. 301

Yoshida, S., Forno, D.A and Cook, S.M. 1971. The laboratory manual for physiological studies in rice IRRI, Los Baneous, Phillipines, pp. 38.

\section{How to cite this article:}

Manjunatha, L., Mamta Sharma, P.R. Saabale, B.M. Ravikumara and Singh, N.P. 2018. Comparative Study on Biochemical Parameters among Ascochyta Blight Infected Moderately Resistant and Susceptible Chickpea Genotypes. Int.J.Curr.Microbiol.App.Sci. 7(10): 21522160. doi: https://doi.org/10.20546/ijcmas.2018.710.247 